\title{
How effective is cryotherapy applied to the nail fold in ingrown toenails?
}

\author{
Çağrı Turan ${ }^{\circledR}$, Tijen Şahin², Hatice Meral Ekşioğlu² \\ ${ }^{1}$ Department of Dermatology and Venereology, Health Sciences University, Erzurum Regional Training and Research Hospital, Erzurum, Turkey. ${ }^{2}$ Depart- \\ ment of Dermatology and Venereology, Health Sciences University, Ankara Health Training and Research Center, Ankara, Turkey.
}

\begin{abstract}
Introduction: There are only two publications in Pubmed on the effectiveness of cryotherapy in ingrown toenails, and they present conflicting results. We aimed to clarify the clinical effectiveness of cryotherapy in onychocryptosis.

Methods: This study retrospectively examined the visual analogue scale (VAS), dermatological life quality index (DLQI), other medical records, and photographs taken before each cryotherapy session and 6-month follow-up in 59 adult patients with ingrown toenails that underwent cryotherapy with a 3-week interval. Cryotherapy effectiveness was assessed by the clinicians' decisions, improvements in VAS and DLQI scores, and granulation tissue. Other factors related to effectiveness and recurrence were also investigated.

Results: After excluding approximately $20 \%$ of patients, for whom the treatment was not effective, this study revealed that recurrence rates in unilateral and bilateral onychocryptosis were $34.2 \%$ and $88.9 \%$, respectively, 6 months after treatment. In patients that responded to the treatment, about 75 to $80 \%$ had excellent symptomatic responses. Excellent symptomatic responses were maintained in about $80 \%$ of patients in remission. We found that foot or toe deformity was associated with treatment ineffectiveness $(p=0.019)$. Age younger than 20 years and bilateral ingrown toenails were also related to recurrence $(p=0.042$ and 0.003 , respectively).

Conclusions: Cryotherapy can be used to greatly and consistently improve the DLQI in suitable ingrown toenails.
\end{abstract}

Keywords: dermatological quality of life index, effectiveness, cryotherapy, recurrence, ingrown toenail, visual analogue scale

Received: 24 October 2019| Returned for modification: 19 January 2020 | Accepted: 28 January 2020

\section{Introduction}

Onychocryptosis or ingrown toenail (IGTN) is a common, painful health problem that causes patients severe discomfort. In $80 \%$ of cases, IGTN is unilateral (1). IGTN is usually associated with a thin spicule formed in the distal-lateral part of a toenail after the oblique cutting of the large, slightly concave nail (2).

Patients usually present with severe pain that greatly affects their quality of life (3). Heifetz divided distal-lateral IGTN, which is the most common form, into three stages (4): stage 1: pain only, stage 2: presence of inflammation, stage 3: presence of granulation tissue.

Depending on the disease severity and the patient's expectations, the various treatment options range from conservative to surgical options. Some of the conventional conservative treatments include taping, cotton wisp, tube insertion, and nail brace (5-8). The advantages of conservative treatments are that they are easy, fast, low-cost methods, and they improve the patient's quality of life. However, there is no strong evidence for the effectiveness or superiority of these conservative methods. The choice of techniques depends on the severity of the clinical status, previous treatments, patient preferences, risk of recurrence, physician skills, and the physical healthcare facilities available.

Cryotherapy is a fast, inexpensive, and simple method that can be used as one of the conservative treatment options, although it is not commonly used in IGTN. There are only two articles in Pubmed, one of which is a letter to the editor, about the effectiveness of cryotherapy for IGTN, and their findings are contradictory $(9,10)$.
This study's primary aim is to evaluate the clinical effectiveness of nail-fold cryotherapy in IGTN and this method's impact on improvements in the visual analogue scale (VAS), dermatology life quality index (DLQI), and granulation tissue. The secondary aim is to determine the factors associated with effectiveness and recurrence.

\section{Methods}

\section{Study population and design}

This retrospective study was carried out by examining the records of patients that presented to the outpatient clinic with IGTN between February 2016 and 2018. This study was conducted in accordance with approval from the Ankara Hospital's Educational Planning and Coordination Board (347/2018). The inclusion criteria were: 17 years or older, lateral subcutaneous IGTN, and absence of active paronychia or completed antibiotic therapy. Exclusion criteria were bilateral IGTN in at least one toe, pincer nail, distal or posterior IGTN, and any treatment for ingrown nails in the past 3 months.

Of 141 outpatients diagnosed with IGTN, 59 (41.8\%) were enrolled in the study. A total of 82 patients were excluded due to age $(n=14)$, treatment by other methods (surgery, $n=44$; nail brace, $n=11)$, missing follow-up data $(n=5)$, and other reasons $(n=8)$. Regardless of the stage, whether patients undergoing nail-fold cryotherapy had a response to treatment was evaluated by the decreases in the DLQI (with a score of o to 30 points) 
and VAS (with a score of o to 10 points for pain) recorded in their files. For patients that did not respond to cryotherapy administered at 3-week intervals, other conservative or surgical treatment options were performed. Data such as demographic characteristics, systemic comorbidities, stage, suspicious predisposing factors, previous treatment, clinical notes at the pre- and post-treatment visits (pain, inflammation, granulation tissue), and VAS and DLQI at every follow-up were obtained from the patient files.

The patients that were followed up after treatment were contacted by telephone 6 months later and information about their latest clinical status, recurrence, and their last DLQI and VAS were obtained. Other treatment options were performed for all patients presenting with increasing complaints within 6 months.

The clinical response after cryotherapy, which is the primary outcome variable of the study, was evaluated based on VAS/DLQI, regression of the granulation tissue, and the clinician's decisions regarding effectiveness or recurrence. Patients were also assessed for cryotherapy-induced pain and other complications.

\section{Cryotherapy procedure in IGTN}

Informed consent was obtained from all patients that underwent cryotherapy. Liquid nitrogen was applied to the lateral nail fold and adjacent nail bed using the open-spray method for 10 seconds regardless of the stage of IGTN, with a double freeze-thaw cycle (CRY-AC ${ }^{\circledR}$, Brymill Cryogenic Systems spray tank and 102-B spray probe). The entire procedure took an average of 3 to 4 minutes. Local anesthesia was not performed before cryotherapy. The study was conducted in line with the latest versions of the Declaration of Helsinki and the Guidelines for Good Clinical Practice.

\section{Statistical analysis}

Data were collected for 59 patients. Pearson's chi-squared test and Fisher's exact test were used for category variables where appropriate. After checking the scale variables with the appropriate normality tests (Kolmogorov-Smirnov or Shapiro-Wilk), independent samples were compared using the appropriate significance tests (Mann-Whitney $U$ test, Kruskal-Wallis $H$, and Spearman's rank correlation coefficient). The Wilcoxon test and Friedman test (with the Dunn-Bonferroni test) were utilized for dependent samples. We also performed a univariate logistic regression for the effectiveness and recurrence variables (as dependent), establishing the crucial influencing factors such as age, sex, predisposing factors, granulation tissue size, stage, bilateral IGTNs, excellent response according to VAS/DLQI results (independent variables), and their odds ratios (OR). A $p$-value $<0.05$ was considered statistically significant. All procedures were conducted using IBM SPSS Statistics 21.0 (IBM Corp. Released 2012. IBM SPSS Statistics for Windows, Version 21.o. Armonk, NY: IBM Corp.) and MS-Excel 2010. We showed the change in granulation tissue in the controls by bar chart and the mean points given to each DLQI question by radar chart.

Table 1 | Distribution based on clinical decision.

\begin{tabular}{|c|c|c|c|c|c|}
\hline \multirow{2}{*}{ After cryotherapy } & \multirow{2}{*}{ Patient status } & \multicolumn{3}{|c|}{ Patient distribution, $n(\%)$} & \multirow{2}{*}{$\begin{array}{c}\text { Toenails, } n \\
\text { failed/treated }\end{array}$} \\
\hline & & 1 IGTN & 2 IGTNs & Total & \\
\hline Ineffective & Removed from follow-up & $9(19.2)$ & $3(25.0)$ & $12(20.3)$ & $13 / 15$ \\
\hline \multirow[t]{2}{*}{ Effective, 6-month recurrence } & Presented to clinic & $5(10.6)$ & $4(33.3)$ & $9(15.3)$ & $10 / 13$ \\
\hline & Did not present to clinict & $8(17.0)$ & $4(33.3)$ & $12(20.3)$ & $13 / 16$ \\
\hline Effective, no recurrence & Remission & $25(53.2)$ & $1(8.3)$ & $26(44.1)$ & $0 / 27$ \\
\hline Total & & $47(100.0)$ & $12(100.0)$ & $59(100.0)$ & $-/ 71$ \\
\hline
\end{tabular}

IGTN = ingrown toenail, $\uparrow$ records updated by telephone at 6-month follow-up.

\section{Results}

The study involved 59 patients ( 28 males and 31 females; $47.5 \%$ vs. $52.5 \%$ ). The participants' ages ranged from 17 to 75 years (mean \pm standard deviation; $36.0 \pm 15.4$ years), with 15 patients $(25.4 \%) 20$ years or younger. Mean body mass index (BMI) was $27.8 \pm 5.4 \mathrm{~kg} /$ $\mathrm{m}^{2}$.

The mean duration of complaints was $6.0 \pm 6.14$ months, ranging from 1 to 24 months (median [interquartile range]; 3 [11] months). It was found that six (10.2\%) women patients had sought medical advice from someone that is not a doctor for treatment.

We performed cryotherapy on 71 nail folds (47 unilateral [79.7\%], 12 bilateral [20.3\%]) of 59 patients. Granulation tissue was present in $34(47.9 \%)$ of 71 IGTNs.

Cryotherapy was performed at an average of two sessions (ranging from one to five sessions). During follow-up, 37 patients $(62.7 \%)$ had bullae at least once due to the procedure, and 22 $(37.3 \%)$ had no bullae. The mean recovery time of the blisters was $3.5 \pm 1.7$ days (ranging from 1 to 7 days). The mean cryotherapyinduced VAS was $8.8 \pm 1.1$ points. We determined that the pain after cryotherapy lasted $2.6 \pm 1.38$ hours (ranging from 1 to 8 hours). No additional complications related to cryotherapy were detected except for secondary infection in three $(5 \%)$ patients.

\section{Evaluation of effectiveness and recurrence}

\section{Distribution based on clinical decision}

A patient-based approach was preferred to a nail-based approach. Namely, if there was no effectiveness in any nails of patients with bilateral IGTNs or if they presented with recurrence, the patient was excluded from the follow-up. The 59 patients included in the study were evaluated by the clinician for the effectiveness of cryotherapy in the treatment sessions. We found treatment to be clinically ineffective in $12(20.3 \%)$ patients. Patients with treatment effectiveness were followed up for 6 months. Whereas nine (15.3\%) of the patients presented with recurrence during the follow-up period, $12(20.3 \%)$ patients did not present to our outpatient clinic despite recurrence; 26 patients $(44.1 \%)$ were still in remission at the 6-month follow-up. After the exclusion of patients for whom treatment effectiveness was not achieved, recurrence rates in the unilateral and bilateral IGTNs were found to be $34.2 \%$ and $88.9 \%$ respectively, and remission rates were $65.8 \%$ and $11.1 \%$ respectively at the end of 6 months (Table 1).

\section{Distribution based on excellent symptomatic response}

We considered patients with zero to one points on the VAS or DLQI upon follow-up to have excellent symptomatic responses. Of 59 patients, $40(67.8 \%)$ had excellent symptomatic responses to the VAS at the first or second follow-up $\left(\mathrm{VAS}_{1-2}\right)$ and $36(61.0 \%)$ to the DLQI at first or second follow-up (DLQI $\left.{ }_{1-2}\right)$. After the exclusion of patients for whom treatment effectiveness was not achieved, of 
the remaining 47 patients, $39(82.9 \%)$ had excellent symptomatic responses to $\mathrm{VAS}_{1-2}$ and $35(74.5 \%)$ to $\mathrm{DLQI}_{1-2}$. Of the 26 patients that were still in remission at the end of 6 months, 22 (84.6\%) had excellent symptomatic responses to VAS at the 6-month follow-up $\left(\mathrm{VAS}_{6}\right)$ and $21(80.8 \%)$ to DLQI at the 6-month follow-up (DLQI $)$ (Table 2).

We found that there was a statistically significant relationship between the complete regression of granulation tissue and excellent symptomatic response to $\mathrm{VAS}_{1-2}$ and $\mathrm{DLQI}_{1-2}$ in 27 patients with unilateral stage 3 IGTNs ( $p=0.018$ and $p<0.001$, respectively). There was no statistically significant difference between the presence and size of granulation tissue $(>5 \mathrm{~mm})$ and the number of cryotherapy sessions ( $p=0.227$ and 0.244 , respectively).

\section{Evaluation of regression in granulation tissues}

Grade of regression according to the size of the granulation tissue and the distribution of clinicians' decisions related to effectiveness are shown in Table 3. Although 88\% ( $\leq 5 \mathrm{~mm}$ : $93.8 \%$; $>5 \mathrm{~mm}$ : $77.8 \%$ ) effectiveness was obtained according to the clinician's decisions, of 25 nails with stage 3 IGTNs, $52.0 \%$ ( $\leq 5 \mathrm{~mm}$ : $68.8 \%$ vs. > $5 \mathrm{~mm}: 22.2 \%$ ) of granulation tissues completely disappeared.

The regression rates obtained in the first and second sessions according to granulation tissue size are shown in a bar chart (Fig. 1). In patients with granulation size of $5 \mathrm{~mm}$ or less, the complete regression rate increased from 27.3 to $81.8 \%$ after the second session; however, the complete regression rate increased from o to $22.2 \%$ in patients with granulation tissue larger than $5 \mathrm{~mm}$.

\section{Investigation of factors related to effectiveness and recurrence}

The findings of all factors thought to be related to effectiveness

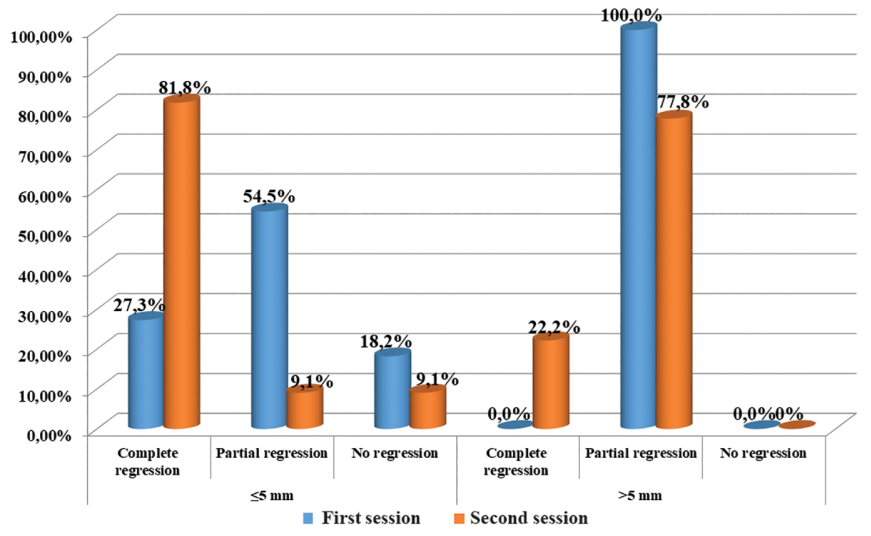

Figure 1 | Regression of the granulation tissue within two consecutive sessions.

Table 2 | Distribution based on excellent symptomatic response (0-1 point).

\begin{tabular}{|c|c|c|c|c|}
\hline \multirow{2}{*}{ After cryotherapy } & \multicolumn{4}{|c|}{ Patients by scale or index, $n(\%)$} \\
\hline & VAS $1-2$ & DLQI1-2 & VAS6 & DLQI6 \\
\hline Ineffective, $n=12$ & $1(8)$ & $1(8)$ & - & - \\
\hline Effective, 6-month recurrence, $n=21$ & $15(71)$ & $13(62)$ & $1(5)$ & $3(14)$ \\
\hline Effective, no recurrence, $n=26$ & $24(92)$ & $22(85)$ & $22(85)$ & $21(81)$ \\
\hline Effective, total, $n=47$ & $39(83)$ & $35(74)$ & $23(49)$ & $24(51)$ \\
\hline Total, $n=59$ & $40(68)$ & $36(61)$ & $23(39)$ & $24(41)$ \\
\hline
\end{tabular}

$\mathrm{VAS}_{1-2}=$ visual analogue scale at first or second follow-up, $\mathrm{VAS}_{6}=$ visual analogue scale at 6 months, DLQI ${ }_{1-2}=$ dermatological quality of life index at first or second follow-up, $\mathrm{DLQI}_{6}=$ dermatological quality of life index at 6 months.

Table 3 | Evaluation of regression in granulation tissues.

\begin{tabular}{|c|c|c|c|c|c|c|}
\hline \multirow{2}{*}{$\begin{array}{l}\text { Basal granulation } \\
\text { tissue size }\end{array}$} & \multicolumn{2}{|c|}{ Clinically effective, $n(\%)$} & \multicolumn{3}{|c|}{ Regression of granulation tissue, $n(\%)$} & \multirow{2}{*}{ Total } \\
\hline & Yes & No & Complete & Partial & None & \\
\hline$\leq 5 \mathrm{~mm}$ & $15(93.8)$ & $1(6.2)$ & $11(68.8)$ & $4(25.0)$ & $1(6.2)$ & $16(100.0)$ \\
\hline$\geq 5 \mathrm{~mm}$ & $7(77.8)$ & $2(22.2)$ & $2(22.2)$ & $7(77.8)$ & $0(0.0)$ & $9(100.0)$ \\
\hline Total & $22(88.0)$ & $3(12.0)$ & $13(52.0)$ & $11(44.0)$ & $1(4.0)$ & $25(100.0)$ \\
\hline
\end{tabular}


comorbidities, or the formation of bullae due to the procedure. There was no significant reduction in the risk of recurrence in patients with excellent symptomatic responses.

Table 4 | Investigation of factors related to effectiveness and recurrence.

\begin{tabular}{|c|c|c|c|c|c|c|c|}
\hline \multirow{2}{*}{ Factor } & & \multicolumn{2}{|c|}{ Effectiveness } & \multirow{2}{*}{$p$-value } & \multicolumn{2}{|c|}{ Recurrence } & \multirow{2}{*}{$p$-value } \\
\hline & & - & + & & + & - & \\
\hline \multicolumn{8}{|l|}{ Ingrown toenails, $n$} \\
\hline Unilateral & & 9 & 38 & \multirow{2}{*}{$0.695 t$} & 12 & 26 & \multirow{2}{*}{$0.003 \dagger$} \\
\hline Bilateral & & 3 & 9 & & 8 & 1 & \\
\hline Total & & 12 & 47 & & 20 & 27 & \\
\hline \multicolumn{8}{|l|}{ Predisposing factors } \\
\hline \multirow{2}{*}{$\mathrm{BMI} \geq 25 \mathrm{~kg} / \mathrm{m} 2$} & $\mathrm{Y}$ & 7 & 26 & \multirow{2}{*}{$0.704 \dagger$} & 7 & 19 & \multirow{2}{*}{$0.270 \dagger$} \\
\hline & $\mathrm{N}$ & 2 & 12 & & 6 & 6 & \\
\hline \multirow{2}{*}{ Incorrect nail cutting, $n$} & $Y$ & 6 & 23 & \multirow{2}{*}{$1.000 t$} & 6 & 17 & \multirow{2}{*}{0.191} \\
\hline & $\mathrm{N}$ & 3 & 15 & & 7 & 8 & \\
\hline \multirow{2}{*}{ Thick or thin nails, $n$} & $\mathrm{Y}$ & 4 & 22 & \multirow{2}{*}{$0.486 t$} & 6 & 16 & \multirow{2}{*}{0.290} \\
\hline & $\mathrm{N}$ & 5 & 16 & & 7 & 9 & \\
\hline Increased nail curvature n & $\mathrm{Y}$ & 5 & 18 & $0724 \mathrm{t}$ & 8 & 10 & 0.207 \\
\hline Increased nall curvature, n & $\mathrm{N}$ & 4 & 20 & 0.1241 & 5 & 15 & 0.207 \\
\hline & $Y$ & 4 & 16 & & 6 & 10 & \\
\hline Inappropriate footwear, $n$ & $\mathrm{~N}$ & 5 & 22 & $1.000 \mathrm{~T}$ & 7 & 15 & 0.115 \\
\hline & $Y$ & 4 & 18 & & 5 & 13 & \\
\hline IInea ungurum, $n$ & $\mathrm{~N}$ & 5 & 20 & $1.000 \mathrm{~T}$ & 8 & 18 & 0.428 \\
\hline & $Y$ & 4 & 13 & & 5 & 8 & \\
\hline Plantar hyperhıdrosıs, $n$ & $\mathrm{~N}$ & 5 & 25 & $0.704 \uparrow$ & 8 & 17 & $0.130 t$ \\
\hline Eamily history $n$ & $Y$ & 1 & 12 & $0410+$ & 5 & 7 & $0714+$ \\
\hline ramily nistory, $n$ & $\mathrm{~N}$ & 8 & 26 & $0.410 \mathrm{~T}$ & 8 & 18 & $0.714 \mathrm{~T}$ \\
\hline & $Y$ & 3 & 9 & & 1 & 8 & \\
\hline Plantar callus, $n$ & $\mathrm{~N}$ & 6 & 29 & $0.6 / 4 \mathrm{~T}$ & 12 & 17 & $0.126 \mathrm{~T}$ \\
\hline & $Y$ & 1 & 10 & & 2 & 8 & \\
\hline Acute trauma, $n$ & $\mathrm{~N}$ & 8 & 28 & $0.663 \mathrm{~T}$ & 11 & 17 & $0.441 \mathrm{~T}$ \\
\hline Font/toe deformity $n$ & $Y$ & 3 & 1 & $0019+$ & 0 & 1 & $1000+$ \\
\hline root/toe derormity, $n$ & $\mathrm{~N}$ & 6 & 37 & 0.0191 & 13 & 24 & 1.0001 \\
\hline Duration of shoe wear, h (IQR) & & $8(6)$ & $8(6)$ & $0.461 \ddagger$ & $8(7)$ & $9(6)$ & $0.525 \ddagger$ \\
\hline Total patients, $n$ & & 9 & 38 & & 13 & 25 & \\
\hline Other possible parameters & & & & & & & \\
\hline Age, y (IQR) & & $36(36)$ & 35 (19) & $0.705 \ddagger$ & $24(18)$ & $36(19)$ & $0.042 \ddagger$ \\
\hline & $M$ & 4 & 18 & & 5 & 13 & \\
\hline Sex, $n$ & $\mathrm{~F}$ & 5 & 20 & $1.000 \dagger$ & 8 & 12 & 0.428 \\
\hline Complaint duration, m (IQR) & & $2(2)$ & $2(8)$ & $0.216 \ddagger$ & $6(11)$ & $2(5)$ & $0.321 \ddagger$ \\
\hline Svctomir comorhidity & $\mathrm{Y}$ & 4 & 14 & 0716 & 2 & 12 & $0077+$ \\
\hline systemıc comorbıdity & $\mathrm{N}$ & 5 & 24 & 0.116 & 11 & 13 & $0.07 / \uparrow$ \\
\hline Diahetec mellituc & $\mathrm{Y}$ & 2 & 5 & $0.605 t$ & 0 & 5 & $0.144 t$ \\
\hline Dlabetes mellitus & $\mathrm{N}$ & 7 & 33 & $0.605 \mathrm{~T}$ & 13 & 20 & $0.144 \mathrm{~T}$ \\
\hline Drocence of aranulation ticсu & $\mathrm{Y}$ & 6 & 21 & 712+ & 7 & 14 & 0900 \\
\hline Presence ol gramutation lissue & $\mathrm{N}$ & 3 & 17 & 0.1131 & 6 & 11 & 0.899 \\
\hline Granulation ticcun cizo & $\leq 5 \mathrm{~mm}$ & 3 & 15 & $367+$ & 5 & 10 & $10 \cap 0+$ \\
\hline Granulatıon tissue sıze & $>5 \mathrm{~mm}$ & 3 & 6 & $0.36 / \mathrm{T}$ & 2 & 4 & $1.000 \mathrm{~T}$ \\
\hline Inflammation at admicsion & $\mathrm{Y}$ & 4 & 19 & $1000+$ & 6 & 13 & 0732 \\
\hline Initammation at aqmission & $\mathrm{N}$ & 5 & 19 & 1.0001 & 7 & 12 & 0.132 \\
\hline & $\mathrm{Y}$ & 1 & 7 & & 3 & 4 & \\
\hline Previous any treatment failure & $\mathrm{N}$ & 8 & 31 & $1.000 \dagger$ & 10 & 21 & $0.6 / 2 \uparrow$ \\
\hline Bullae at leact 1 time due to nrocedure & $Y$ & 4 & 26 & & 8 & 18 & \\
\hline Butlae at least 1 time due to procedure & $\mathrm{N}$ & 5 & 10 & $0.135 \mathrm{~T}$ & 5 & 5 & $0.440 \mathrm{~T}$ \\
\hline Sessions, $n$ (IQR) & & $2(0)$ & $2(1)$ & $0.247 \ddagger$ & $2(1)$ & $2(1)$ & $0.759 \ddagger$ \\
\hline $\mathrm{VAS}_{1}$, & $\leq 1$ point & - & - & _- & 4 & 15 & 0.087 \\
\hline VAS $1-2$ & $>1$ points & - & - & - & 9 & 10 & 0.087 \\
\hline $\mathrm{DLOI}_{1-2}$ & $\leq 1$ point & - & - & _- & 7 & 13 & 0.914 \\
\hline DLQ11-2 & $>1$ points & - & - & & 6 & 12 & 0.914 \\
\hline
\end{tabular}

$\mathrm{Y}=$ yes, $\mathrm{N}=\mathrm{no}, \mathrm{BMI}=$ body mass index, $\mathrm{M}=$ male, $\mathrm{F}=$ female, $\mathrm{h}=$ hours, $\mathrm{y}=$ years, $\mathrm{m}=$ months, IQR = interquartile range, $\mathrm{VAS} \mathrm{S}_{1-2}=$ visual analogue $\mathrm{scale}$ at first or second follow-up, $\mathrm{DLQI}_{1-2}=$ dermatological quality of life index at first or second follow-up, †Fisher’s exact test, $¥$ Mann-Whitney $U$ test. Significant values are shown in bold.

Table 5 | Factors related to effectiveness or recurrence.

\begin{tabular}{|c|c|c|c|c|c|c|}
\hline \multirow{2}{*}{$\begin{array}{l}\text { Univariate logistic } \\
\text { regression analysis }\end{array}$} & \multirow{2}{*}{$\begin{array}{c}\text { Regression } \\
\text { coefficient }(\beta i)\end{array}$} & \multirow{2}{*}{ Odds ratio } & \multicolumn{2}{|c|}{$95 \% \mathrm{Cl}$} & \multirow{2}{*}{ Wald value } & \multirow{2}{*}{$p$-value } \\
\hline & & & Lower & Upper & & \\
\hline \multicolumn{7}{|l|}{ Effectiveness Foot } \\
\hline Toe deformity & 2.92 & 18.50 & 1.64 & 208.46 & 5.58 & 0.018 \\
\hline \multicolumn{7}{|l|}{ Recurrences } \\
\hline Bilateral ingrown toenails & 2.73 & 15.39 & 1.73 & 136.67 & 6.02 & 0.014 \\
\hline Age $\leq 20$ & 1.84 & 6.29 & 1.24 & 31.96 & 4.91 & 0.027 \\
\hline
\end{tabular}

$\mathrm{Cl}=$ confidence interval. 
ranging from 1.5 to 9 points). The mean DLQI at baseline (DLQI $)$ was $9.47 \pm 5.24$ (the median 9 [8], ranging from 1 to 24 points). Also, there were statistically significant positive correlations (low, medium, medium, and very high, respectively) between the peerto-peer points on the VAS and DLQI at the baseline exam, the first and second follow-ups, and the 6-month follow-up (VAS $\mathrm{VA-1-2-6}$ and DLQI ${ }_{0-1-2-6}$ ) (baseline: $r=0.359, p=0.005$; first follow-up: $r$ $=0.637, p<0.001$; second follow-up: $r=0.683, p<0.001$; 6-month follow-up: $r=0.920 ; p<0.001$, respectively). Although the $\mathrm{VAS}_{\mathrm{o}}$ of the 12 patients that were switched to alternative treatments due to ineffectiveness was statistically significantly higher than the last VAS in the follow-up, the DLQI ${ }_{0}$ did not show a statistically significant difference from the last DLQI in the follow-up ( $p=0.009$, 0.009, and 0.385). Indeed, no statistically significant correlation was found between the last VAS and DLQI in patients with treatment ineffectiveness $(r=0.498 ; p=0.099)$.

When factors that could potentially affect VAS and DLQI such as age, sex, BMI, number of IGTNs, stage, and complaint duration were evaluated statistically, it was found that there was a weak positive correlation only between complaint duration and $\mathrm{VAS}_{\mathrm{O}}$ and $\mathrm{DLQI}_{\mathrm{O}}(r=0.323, p=0.012$; and $r=0.301, p=0.021$, respectively).

The patients were categorized according to their $\mathrm{DLQI}_{\mathrm{O}}$ points into five groups as no impact (o-1 point, 1.7\%), small impact (2-5 points, $25.4 \%$ ), moderate impact (6-10 points, 33.9\%), very large impact (11-20 points, 37.3\%), and extremely large impact (21-30
Question 3 (1.32 \pm 1.12$)$, Question 7 (1.14 \pm 1.01$)$, Question 5 (0.98 \pm 1.09), Question 2 (o.89 \pm 1.12$)$, Question 6 (o.81 \pm 1.17$)$, Question 8 (0.41 \pm 0.90$)$, and Question $9(0.38 \pm 0.26)$. Question 10 received no points from the patients. The mean scores recorded were 9.47 for $\mathrm{DLQI}_{0}, 4.58$ for $\mathrm{DLQI}_{1}, 2.07$ for $\mathrm{DLQI}_{2}$, and 3.29 for DLQI .

There were statistically significant differences between the peer-to-peer points on the $\mathrm{DLQI}_{\mathrm{O}-1-2-6}$ and $\mathrm{VAS}_{\mathrm{O}-1-2-6}$ (Table 6). When compared using the appropriate statistical tests, only DLQI6 was not different from $\mathrm{DLQI}_{1}$ and $\mathrm{DLQI}_{2}$. Similarly, VAS 6 was not different from $\mathrm{VAS}_{1}$ and $\mathrm{VAS}_{2}$ (Table 7). When $\mathrm{VAS}_{0}, \mathrm{VAS}_{6}$, $\mathrm{DLQI}_{0}$, and $\mathrm{DLQI}_{6}$ were compared in patients that had recurrences after 6 months, the baseline mean ranking scores were found to be significantly higher than those of the 6-month follow-up ( $p=0.04$ and 0.04 , respectively).

\section{Discussion}

Cryotherapy reduces regional pain by causing reversible functional changes in the peripheral nerves. It is also beneficial in eradicating infection and destroying granulation tissue $(11,12)$. Sonnex et al. proceeded from the idea that cryotherapy would be effective on three components: pain, inflammation, and granulation tissue, which are the main features of IGTN, when they published the first report on using cryotherapy in IGTN in 1985 (9). Using the same method, Masters reported disappointing results in 1991 and described the process as a waste of time (10).

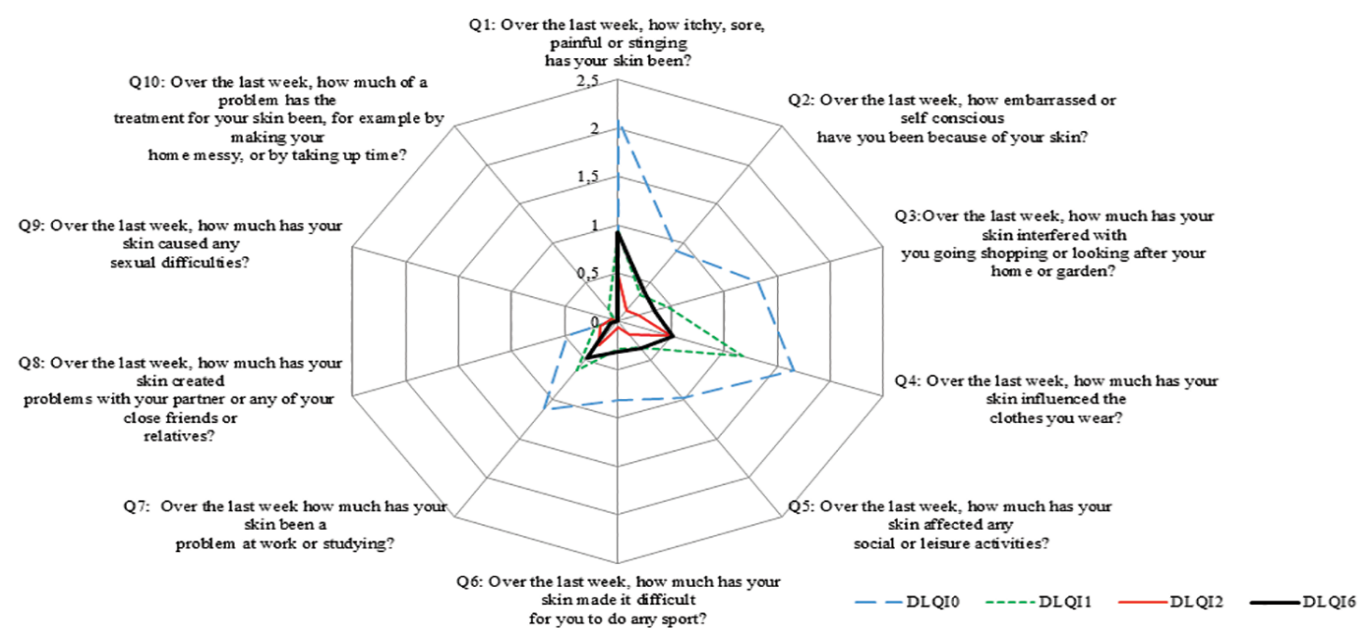

Figure 2 | Mean points of answers to each question of dermatological quality of life index.

Table 6 | Differences by scale/index between peer-to-peer points on the $\mathrm{VAS}_{0-1-2-6}$ and $\mathrm{DLQI}_{0-1-2-6}$.

\begin{tabular}{|c|c|c|c|c|c|c|c|}
\hline & \multirow{2}{*}{$n$} & \multicolumn{4}{|c|}{ Median (IQR) } & \multirow{2}{*}{$x^{2}$} & \multirow{2}{*}{$p$-value } \\
\hline & & Baseline & First follow-up & Second follow-up & 6-month follow-up & & \\
\hline VAS & 23 & $7.0(3.5)$ & $3(2.0)$ & $0(1.0)$ & $0.5(2.5)$ & 56.8 & $<0.001$ \\
\hline DLQI & 23 & $8.5(8.8)$ & $3(5.3)$ & $0(1.0)$ & $0.5(2.5)$ & 46.1 & $<0.001$ \\
\hline
\end{tabular}

$n=$ number of patients, IQR = interquartile range, VAS = visual analogue scale, DLQI = dermatological quality of life index. Significant values are shown in bold.

points, $1.7 \%$ ) on the patient's life.

The radar chart in Figure 2 was made by placing each of the 10 DLQI questions in a corner and marking the diagonals' distance from the center to the corner, limited to three units for the maximum score of each question ( $0=$ not at all, $1=$ a little, $2=\mathrm{a}$ lot, $3=$ very much). It can be imagined that the area of the polygon formed by connecting the mean DLQI points obtained from each question consecutively with one another corresponds to the perceived impact on patients' dermatological quality of life.

When $\mathrm{DLQI}_{O}$ in the figure was examined, the patient scores were ranked from the highest to the lowest by question, resulting in this order: Question 1 (2.08 \pm 0.77$)$, Question 4 (1.66 \pm 1.14$)$,
Table 7 | Differences by visit between peer-to-peer points on the VAS and DLQI.

\begin{tabular}{lccc}
\hline VAS & $p$-value & DLQI & $p$-value \\
\hline VAS $_{0}-$ VAS $_{1}$ & $\mathbf{0 . 0 0 5}$ & DLQI $_{0}-\mathrm{DLQI}_{1}$ & 0.021 \\
VAS $_{0}-$ VAS $_{2}$ & $<\mathbf{0 . 0 0 1}$ & $\mathrm{DLQI}_{0}-\mathrm{DLQI}_{2}$ & $<\mathbf{0 . 0 0 1}$ \\
VAS $_{0}-$ VAS $_{6}$ & $<\mathbf{0 . 0 0 1}$ & $\mathrm{DLQI}_{0}-\mathrm{DLQI}_{6}$ & $<\mathbf{0 . 0 0 1}$ \\
VAS $_{1}-$ VAS $_{2}$ & $\mathbf{0 . 0 0 2}$ & $\mathrm{DLQI}_{1}-\mathrm{DLQI}_{2}$ & $\mathbf{0 . 0 1 0}$ \\
VAS $_{1}-$ VAS $_{6}$ & 0.208 & $\mathrm{DLQI}_{1}-\mathrm{DLQI}_{6}$ & 0.371 \\
VAS $_{2}-$ VAS $_{6}$ & 0.920 & DLQI $_{2}-\mathrm{DLQI}_{6}$ & 1.000
\end{tabular}

VAS = visual analogue scale, DLQI = dermatological quality of life index, VAS $=$ VAS at baseline, VAS $_{1}=$ VAS at first follow-up, $V^{\prime} S_{2}=$ VAS at second followup, $\mathrm{VAS}_{6}=\mathrm{VAS}$ at 6 months, DLQI $=\mathrm{DLQI}$ at baseline, $\mathrm{DLQI}_{1}=\mathrm{DLQI}$ at first follow-up, $\mathrm{DLQI}{ }_{2}=\mathrm{DLQI}$ at second follow-up, DLQI $6=\mathrm{DLQI}$ at 6 months, $\dagger$ post hoc analysis and Bonferroni correction applied. Significant values are shown in bold. 


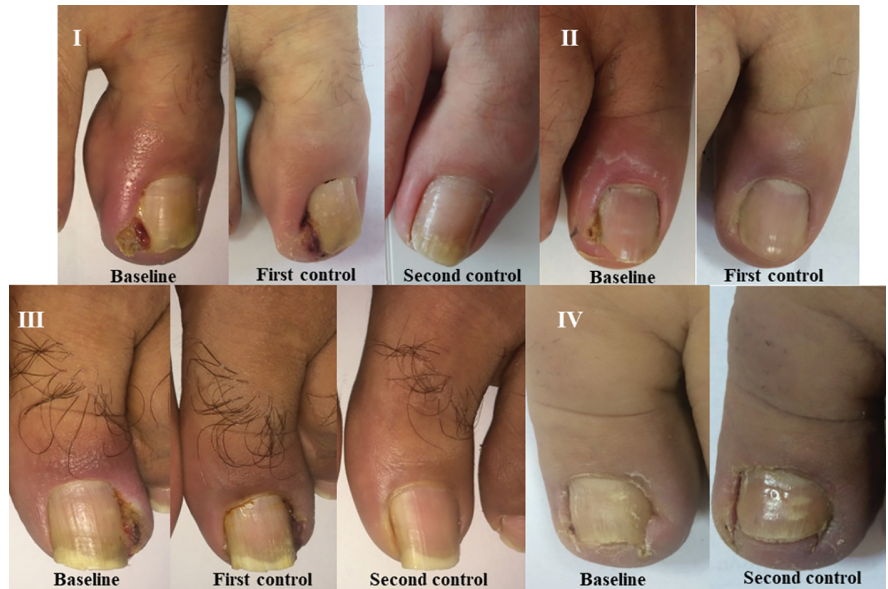

Figure 3 | Complete regression of granulation tissue $(\leq 5 \mathrm{~mm})$.

I. VAS 0 -VAS 1 -VAS 2 : 5-4-1 points, DLQI 0 -DLQI 1 -DLQI 2 : 12-6-0 points, respectively. II. $\mathrm{VAS}_{0}-\mathrm{VAS}_{1}: 3,5-0$ points, $\mathrm{DLQI}_{0}-\mathrm{DLQI}_{1}-\mathrm{DLQI}_{2}: 2-0$ points, respectively. III. VAS $-\mathrm{VAS}_{1}-\mathrm{VAS}_{2}:$ 7,5-3-1 points, DLQI 0 -DLQI $-\mathrm{DLQI}_{2}: 24-7-1$ points, respectively. IV. $\mathrm{VAS}_{0}-\mathrm{VAS}_{1}-\mathrm{VAS}_{2}:$ 5-3-0,5 points, $\mathrm{DLQI}_{0}-\mathrm{DLQI}_{1}-\mathrm{DLQI}_{2}:$ 7-5-1 points, respectively.

VAS $=$ visual analogue scale, VAS $_{0}=$ VAS at baseline, VAS $_{1}=$ VAS at first control, $\mathrm{VAS}_{2}=$ VAS at second control, DLQI: dermatological quality of life index, DLQI $=\mathrm{DLQI}$ at baseline, $\mathrm{DLQI}_{1}=\mathrm{DLQI}$ at first control, $\mathrm{DLQI}_{2}=\mathrm{DLQ}$ at second control.

\section{Effectiveness and recurrence}

The publications on this subject to date are summarized in Table 8. It is difficult to compare these studies because of their differences, such as performing the cryotherapy with different protocols, including patients with single or double IGTNs, and handling the two effectiveness criteria (granulation tissue and pain) differently. In Table 8, effectiveness and recurrence rates are given by the proportion of the number of patients at risk, regardless of the number and stage of IGTN. The number of sessions, freezing time, number of patients, and stage of IGTN varied in the studies; consequently, the effectiveness and recurrence rates varied significantly, ranging between 71.4 and $100 \%$ and between 30 and $75 \%$, respectively $(9,10,13)$. Because cryotherapy was performed in a different protocol from Sonnex et al. (10 seconds freezing time, double freezethaw cycle; mean two sessions), treatment effectiveness may have decreased from 100 to $79.7 \%$. In our study, after excluding approximately $20 \%$ of patients with no treatment effectiveness, 65.8 and $11.1 \%$ of patients with unilateral and bilateral IGTNs were still in remission after 6 months, respectively.

The results of conservative treatments can be objectively evalTable 8 | Findings of similar studies to date.

\begin{tabular}{|c|c|c|c|c|c|c|}
\hline Study & $\begin{array}{c}\text { Sample } \\
\text { characteristics }\end{array}$ & Protocol & Effectiveness & Recurrence & $\begin{array}{l}\text { Recurrence time / } \\
\text { follow-up }\end{array}$ & Complications \\
\hline Sonnex \& Dawber 1985 & $\begin{array}{l}44 \text { patients, } 48 \text { IGTN } \\
\text { (stage } 1-3 \text { ) }\end{array}$ & $\begin{array}{l}30 \text { seconds open } \\
\text { spray method, single } \\
\text { freeze-thaw cycle, } \\
1 \text { session }\end{array}$ & $\begin{array}{l}44 \text { patients } \\
(100 \%)\end{array}$ & $\begin{array}{l}\text { 20/44 patients } \\
\quad(45.5 \%) \dagger\end{array}$ & $1-3 / 13-18$ months & $\begin{array}{c}\text { Onycholysis (9\%), } \\
\text { leukonychia (11\%), } \\
\text { pain }\end{array}$ \\
\hline Masters 1991 & $\begin{array}{c}20 \text { patients, ? IGTN } \\
\text { (stage?) }\end{array}$ & $\begin{array}{c}30 \text { seconds open } \\
\text { spray method, single } \\
\text { freeze-thaw cycle, } \\
1 \text { session }\end{array}$ & $?$ & $\begin{array}{c}\text { 15/20 patients } \\
(75 \%)\end{array}$ & $?$ & Pain \\
\hline Kaya et al. 1999 & $\begin{array}{l}14 \text { patients, } 14 \text { IGTN } \\
\text { (stage } 3 \text { only) }\end{array}$ & $\begin{array}{l}15-25 \text { seconds open } \\
\text { spray method, double } \\
\text { freeze-thaw cycles, } \\
1-2 \text { sessions }\end{array}$ & $\begin{array}{l}10 \text { patients } \\
(71.4 \%)\end{array}$ & $\begin{array}{c}\text { 3/10 patients } \\
(30 \%)\end{array}$ & ? / 8.5 months & $\begin{array}{l}\text { Pain, secondary } \\
\text { infection }\end{array}$ \\
\hline This study & $\begin{array}{l}59 \text { patients, } 71 \text { IGTN } \\
\text { (stage } 1-3 \text { ) }\end{array}$ & $\begin{array}{l}10 \text { seconds open } \\
\text { spray method, double } \\
\text { freeze-thaw cycles, } \\
1-5 \text { sessions }\end{array}$ & $\begin{array}{l}47 \text { patients } \\
(79.7 \%) \ddagger\end{array}$ & $\begin{array}{l}\text { 21/47 patients } \\
(44.7 \%)\end{array}$ & $1-4$ / 6 months & $\begin{array}{c}\text { Secondary infection } \\
(5 \%) \text {, bullae }(63 \%), \\
\text { pain }\end{array}$ \\
\hline
\end{tabular}

IGTN = ingrown toenail, $\dagger$ successful results obtained in $28(63.6 \%)$ patients due to absence of recurrence in four of six patients that underwent second session after recurrence, $\neq$ effectiveness criterion was complete regression in granulation tissue.

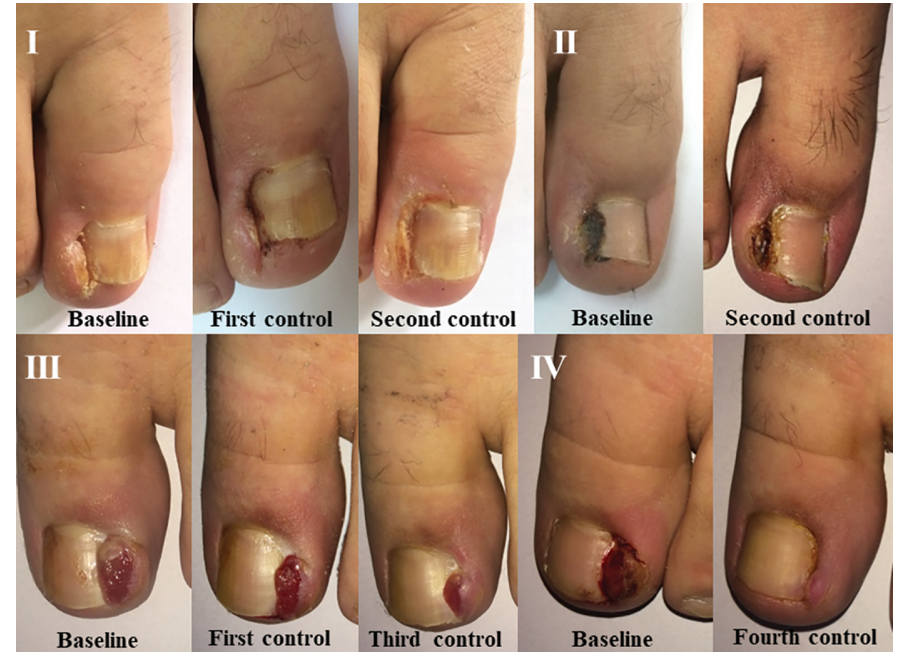

Figure 4 | Partial regression of granulation tissue (> $5 \mathrm{~mm}$ ). tively. II. VAS -VAS $_{1}: 7,5-2,5-1,5$ points, $\mathrm{DLQI}_{0}-\mathrm{DLQI}_{1}-\mathrm{DLQI}_{2}: 13-7-2$ points, respectively. III. $\mathrm{VAS}_{0}-\mathrm{VAS}_{1}-\mathrm{VAS}_{2}: 3-2-0,5$ points, DLQI $-\mathrm{DLQI}_{1}-\mathrm{DLQI}_{2}: 3-1-1$ points, respectively. IV. VAS $-V^{-V_{1}}-\mathrm{VAS}_{2}: 3,5-2,5-0,5$ points, $D L Q I_{0}-\mathrm{DLQI}_{1}$ $\mathrm{DLQI}_{2}$ : 3-1-0 points, respectively. Patients II and III were excluded from followup due to lack of treatment efficacy.

VAS $=$ visual analogue scale, VAS $_{0}=$ VAS at baseline, VAS $_{1}=$ VAS at first control, $\mathrm{VAS}_{2}=\mathrm{VAS}$ at second control, DLQI: dermatological quality of life index, DLQI $=\mathrm{DLQI}$ at baseline, $\mathrm{DLQI}_{1}=\mathrm{DLQI}$ at first control, $\mathrm{DLQI}_{2}=\mathrm{DLQI}$ at second control.

uated on a scale. This is because, unlike the results of surgical methods, it is possible to obtain partial responses and difficult to estimate the limits of success. However, no scales such as the VAS or the DLQI were used in any prior study, and treatment success was interpreted subjectively according to the clinician's decision. In this study, the VAS and DLQI points obtained during the follow-up decreased significantly after each session. At the end of 6 months, $\mathrm{VAS}_{6}$ and $\mathrm{DLQI}_{6}$ were not statistically different from $\mathrm{VAS}_{1-2}$ and $\mathrm{DLQI}_{1-2}$, and were significantly lower than the baseline level. Although there was a significant correlation between peerto-peer points on the VAS and DLQI, there was no correlation between patients with no effectiveness. The statistically significant decrease in VAS in these patients did not clinically reflect in the DLQI, and these patients were then excluded from follow-up. Of patients with effectiveness, 83 and $74 \%$ had excellent symptomatic response according to $\mathrm{VAS}_{1-2}$ and $\mathrm{DLQI}_{1-2}$, respectively. After 6 months, excellent symptomatic responses were maintained in 49 and $51 \%$ of patients in the same group, respectively. From another point of view, excellent symptomatic responses were maintained
I. $\mathrm{VAS}_{0}-\mathrm{VAS}_{1}-\mathrm{VAS}_{2}$ : 2,5-1-0 points, $\mathrm{DLQI}_{0}-\mathrm{DLQI}_{1}-\mathrm{DLQI}_{2}: 13-4-0$ points, respec- 
in 85 and $81 \%$ of patients in remission according to the $\mathrm{VAS}_{6}$ and DLQI $_{6}$, respectively.

Unlike other studies, Kaya et al. evaluated the effectiveness of the procedure in patients with only stage 3 IGTN that underwent cryotherapy with a similar protocol but with longer freezing time (15-25 seconds). However, success was defined as complete regression of granulation tissue in their study. In this case, they were able to attain an effectiveness rate of $71.4 \%$. In our study, the treatment was effective in $93.8 \%$ of those with granulation tissue less than $5 \mathrm{~mm}$, whereas $68.8 \%$ had complete regression response after two sessions. Only $22 \%$ of the patients with granulation tissue larger than $5 \mathrm{~mm}$ had complete regression of granulation tissue. Complete granulation tissue response was obtained in $52 \%$ of stage 3 IGTNs, and effectiveness was achieved in $88 \%$ of the patients, assuming adequate symptomatic response despite the partial regression of granulation tissue in $36 \%$ of the patients. In other words, $75 \%$ of the patients with partial regression of granulation tissue were included in the effective treatment group. That the number of cryotherapy sessions was not different according to the stage and granulation tissue size indicates that the patients discontinued treatment with the improvement in pain. In Figures 3 and 4, a total of eight patients with complete and partial regression of granulation tissue are presented with their VAS and DLQI points.

The complete regression rate increased from 27.3 to $81.8 \%$ after the second session in patients with granulation tissue of $5 \mathrm{~mm}$ or less; however, this rate increased from o to $22.2 \%$ in patients with granulation tissue larger than $5 \mathrm{~mm}$. Based on this, it appears that a higher rate of complete regression response was obtained in patients with smaller granulation tissue, and that the response rate could be increased by repeated applications. On the other hand, it is important to keep in mind that patient compliance decreases as the number of required sessions increases.

The complete formation of cryonecrosis is essential in order for treatment to be effective (12). For this reason, connective tissue damage must occur in order to obtain complete regression in the granulation tissue. Although cryotherapy is a procedure that does non-specific damage to the cell, because the physiology of each cell and tissue is different, it can cause damage at different temperatures or application times, depending on the cell types. Although melanocytes and pilosebaceous glands are very sensitive to cryotherapy, the temperature required to damage fibroblasts, nerve cells, and neoplasms is much lower (12). As applied in our study, the method's effectiveness can be increased by using a double freeze-thaw cycle to reach sufficient cryonecrosis. However, our findings also show that if the freezing time was kept shorteven if a double freeze-thaw cycle was used-the effectiveness did not increase sufficiently, especially in those with granulation tissue larger than $5 \mathrm{~mm}$. It appears that in the case of IGTN, it is necessary to keep the freezing time longer than 30 seconds and apply multiple sessions in order to achieve granulation tissue damage.

In our study, recurrence was detected in 34.2 and $88.9 \%$ in the unilateral and bilateral IGTNs after 6 months, respectively. In the study of Sonnex et al., only four patients had bilateral IGTNs, and $45.5 \%$ of the patients had a recurrence within 13 to 18 months after one session. Masters reported that he tried the same technique in 20 patients but abandoned it after observing a 75\% recurrence rate and noting that the procedure was very uncomfortable without local anesthesia (10). However, Masters did not share data on the characteristics of the patients studied. The recurrence rate of bilateral IGTNs in our study makes us think that the high recurrence rate reported by Masters may be related to the patients' number of IGTNs. Although it was evaluated only in a small sample with unilateral stage 3 IGTN, the lowest recurrence rates were reported as $30 \%$ within 8.5 months by Kaya et al. (13). Because VAS and DLQI, rather than granulation tissue, were evaluated in the detection of recurrence in our study, it would be inappropriate to compare our results with those of Kaya et al.

\section{Complications}

Periungual cryotherapy is known to be a very painful procedure. In this study, cryotherapy was performed with a 10-second, double-freeze-thaw cycle in order to reduce complication rates, increase patient compliance, and allow the procedure to be performed without local anesthesia. The cryotherapy-induced VAS was calculated as $8.8 \pm 1.1$ points. There was a mean of $2.6 \pm 1.4$ hours of ongoing pain. It was determined that $62.7 \%$ of the patients had minimum of one bulla, which healed within a mean of $3.5 \pm 1.7$ days. A secondary infection developed in $5 \%$ of patients during follow-up. No additional complications such as scarring, neuropathy, pigmentation disorder, leukonychia, onycholysis, pyogenic granuloma, or nail dystrophy due to cryotherapy were observed. Sonnex et al. reported that patients needed analgesics for a maximum of 2 days after the procedure. In addition, leukonychia developed in $11 \%$ and painless onycholysis in $9 \%$ of the patients, but these two complications resolved spontaneously in 2 to 3 months. It was reported that scarring did not develop despite freezing for 30 seconds (9). In our study, only three patients needed analgesics on the day of cryotherapy. Damage to the onycho-dermal band is involved in the pathogenesis of onycholysis (14). When 30 seconds of freezing time was used, it was thought that $9 \%$ of the patients had experienced excessive tissue damage. Therefore, individualization of the freezing time would be necessary to prevent this complication. In our study, leukonychia and onycholysis did not develop due to the use of a freezing time of 10 seconds. The procedure seems to be well tolerated except for short but severe pain. Serour et al. reported in a randomized, doubleblind, placebo-controlled study that topical anesthetic cream application with occlusion for 1 hour before digital nerve block in IGTN did not lead to a reduction in pain due to the injection. They determined the mean VAS points due to digital block anesthesia performed without topical anesthesia as $3.2 \pm 1.0$ (15). Considering that pain resolved after approximately 2 hours, performing digital block anesthesia will increase comfort during and after the procedure, and it will be feasible to work with long freezing times of 30 seconds and achieve more effective results. As Serour et al. reported, VAS due to digital infiltration anesthesia is substantially lower than the cryotherapy-induced VAS detected in this study. Given these data, we concluded that digital block anesthesia must be performed before cryotherapy to the nail fold.

\section{Conditions associated with effectiveness/recurrence}

Among the accepted predisposing factors for IGTN given in Table 4, only the presence of foot/toe deformity increased the risk of ineffectiveness by 18.5 times (1.642; 208.462). No predisposing factors were associated with recurrence. Although there was no significant relationship between age and effectiveness, the risk of recurrence decreased with increasing age. The risk of recurrence increases by $6.3(1.239 ; 31.956)$ times in patients 17 to 20 years of age. This finding raises the question of whether adolescents expe- 
rience more frequent recurrence of IGTNs after the procedure. Although there is no significant relationship between the number of IGTNs and effectiveness; the risk of recurrence was increased by $15.4(1.73 ; 136.67)$ times in bilateral IGTNs. Therefore, this method should not be preferred in the treatment of patients with foot/toe deformity or multiple IGTNs. Similar to our study, Kayalar et al. reported that the risk of recurrence was significantly increased by 8.9 times in patients with multiple IGTNs that underwent partial surgical matrixectomy; although there was no statistically significant relationship between recurrence and age, previous surgery, stage, or duration of complaints (16).

In this study, the presence and size of granulation tissue were not associated with effectiveness and recurrence. Thus, we attached more importance to the VAS and DLQI compared to granulation tissue response in detecting effectiveness and recurrence. Moreover, the last granulation tissue responses of some patients with effectiveness were not recorded, and no granulation tissue could be evaluated after 6 months. Kaya et al. reported that the recurrence risk of granulation tissue was increased in those with large granulation tissue size, according to their observations (13). In this study, it was not possible to evaluate how granulation tissue affected the risk of recurrence.

\section{VAS and DLQI}

Despite its high incidence, the effect of IGTN on the DLQI was discussed in only one study in the literature. Patients are most uncomfortable with the impact of IGTN on daily activities (Questions 3 and 7) such as shopping, household and garden work, and social life. These are followed by difficulty wearing shoes and a sense of embarrassment, and a negative impact on sports, work, and school life. It was found that IGTN affects relationships with close friends and relatives very little and does not affect sexual life at all (3). The Turkish validity and reliability study of DLQI was conducted by Öztürkcan et al. (17). In our study, the patient scores on individual DLQI questions were ranked from the highest to the lowest as follows: Question 1 (pain), Question 4 (shoe preference), Question 3 (shopping, household and garden work), Question 7 (work and school life), Question 5 (social activity), Question 2 (sense of embarrassment), Question 6 (sports), and Question 8 (relationships with close friends and relatives).

In our study, the mean $\mathrm{VAS}_{\text {o }}$ was $5.94 \pm 0.25$, and the mean of the $\mathrm{DLQI}_{0}$ was $9.47 \pm 5.24$. Borges et al. calculated the mean of the DLQI in IGTN as $8.3 \pm 5.7$ (21). The mean DLQI o points in IGTN $(9.47 \pm 5.24)$ were higher than in chronic urticaria $(4.8 \pm 5.1)$, atopic dermatitis (6.1 \pm 5.5$)$, alopecia areata (6.3 \pm 6.3$)$, and chronic hand eczema $(7.1 \pm 6.0)$, but lower than chronic leg ulcer (13.4 \pm 2.6) (18-21).

According to this study, only $25 \%$ of patients with IGTN sought treatment when their complaints were mild. These results confirm that IGTN is a neglected disease $(1,22)$. This is further supported by the fact that the VASo and $\mathrm{DLQI}_{0}$ of patients with recurrence at the end of 6 months were significantly higher than their $\mathrm{VAS}_{6}$ and DLQI6. The reason that these patients did not seek treatment despite experiencing recurrence is that their quality of life was not affected as much as it had been 6 months before. This positive and important but weak correlation between the duration of IGTN and $\mathrm{VAS}_{\mathrm{o}}$ and $\mathrm{DLQI}$ o may contribute to our understanding of the delay in outpatient admissions. It was also remarkable that the presence of granulation tissue and the number of ingrown nails did not affect $\mathrm{VAS}_{\mathrm{o}}$ and DLQI . $_{\text {. }}$

\section{Advantages and limitations of the study}

This investigation is noteworthy because it offers useful results for daily clinical practice. The study, which uses the shortest freezing time in the indication of the IGTN, provides essential clues to determine procedure protocols comparable to other studies in terms of success rates. This study is the first to determine the factors associated with effectiveness and recurrence in patients treated with cryotherapy and provide comprehensive results. The correlation between VAS and DLQI in IGTN has not been evaluated previously, and the value of these two scales in the treatment follow-up was demonstrated for the first time.

This study has some limitations, such as a small number of patients and short follow-up time. Granulation tissue response was considered less important than the VAS and DLQI in the evaluation of effectiveness. The last status and recurrence of granulation tissue could not be evaluated. Prospective studies with more patients are needed to demonstrate the effectiveness of cryotherapy.

\section{Conclusions}

Many conservative treatment methods are simple and inexpensive, but the duration of administration is long, and the recurrence rate is high $(5,6)$. Cryotherapy is an easy and quick outpatient procedure. The cost is less than other conservative and surgical methods. The most important advantages of cryotherapy are that it eliminates subjective complaints in a short time, does not cause loss of working days, and is a very practical method, as stated in other studies $(9,13)$. Another important advantage is that it can be used effectively during pregnancy, which is a risk factor for IGTN (23). It is also possible to use cryotherapy in combination with other conservative or surgical treatment methods, thus achieving better results (24). If not used as the preferred treatment in patients with foot/toe deformity, 20 years of age and younger, with multiple IGTNs, and granulation tissue larger than $5 \mathrm{~mm}$, the effectiveness rate will increase, and the recurrence rates will decrease. Performing infiltration anesthesia with at least 30 seconds of freezing time, especially in patients with stage 3 IGTNs, will increase the effectiveness of the procedure, reduce the number of necessary sessions, and increase patient compliance. As seen in this study, long-lasting improvement in DLQI can be achieved even with short freezing time applications. Therefore, individualizing the freezing time according to the presence and size of granulation tissue with the experience gained will increase effectiveness without increasing complication rates. To summarize, cryotherapy can be used to greatly and consistently improve the dermatological quality of life in suitable IGTNs.

This study was presented as a talk at the twenty-seventh National Dermatology Congress. (Regnum Carya Hotel, Antalya, Turkey, October 16th-20th, 2018) 


\section{References}

1. Khunger N, Kandhari R. Ingrown toenails. Indian J Dermatol Venereol Leprol. 2012;78:279-89.

2. Piraccini BM. Nail disorders: a practical guide to diagnosis and management. Springer; 2014.

3. Borges APP, Pelafsky VPC, Miot LDB, Miot HA. Quality of life with ingrown toenails: a cross-sectional study. Dermatol Surg. 2017;43:751-3.

4. Heifetz CJ. Operative management of ingrown toenail. Mo Med. 1945;42:213-6.

5. Watabe A, Yamasaki K, Hashimoto A, Aiba S. Retrospective evaluation of conservative treatment for 140 ingrown toenails with a novel taping procedure. Acta Derm Venereol. 2015;95:822-5.

6. Du JF, Xi XY, Liu ZH. Successful conservative treatment with cotton wisp for ingrown toenail with granulation. Dermatol Ther. 2016;29:486-7.

7. AlGhamdi KM, Khurram $\mathrm{H}$. Nail tube splinting method versus lateral nail avulsion with phenol matricectomy: a prospective randomized comparative clinical trial for ingrown toenail treatment. Dermatol Surg. 2014;40:1214-20.

8. Erdoğan FG, Güven M, Elhan AH, Gürler A. Effectiveness of nail brace treatment for ingrown nails. Turkderm. 2010;44:88-91.

9. Sonnex TS, Dawber RP. Treatment of ingrowing toenails with liquid nitrogen spray cryotherapy. Br Med J (Clin Res Ed). 1985;291:173-5.

10. Masters N. Cryotherapy ineffective for ingrowing toenails. Br J Gen Pract. 1991; 41:433-4.

11. Calandria L. Cryoanalgesia for post-herpetic neuralgia: a new treatment. Int J Dermatol. 2011;50:746-50.

12. Gage AA, Baust J. Mechanisms of tissue injury in cryosurgery. Cryobiology. 1998;37:171-86.

13. Kaya İ, Aydıngöz İE, Güney O, Candan İ. Tırnak batması tedavisinde iki yöntemin karşılaştırılması [Comparison of two methods in the treatment of ingrown toenail]. Türkiye Klinikleri Dermatoloji Dergisi. 1999;9:6-10. Turkish.
14. de Berker D. Nail anatomy. Clin Dermatol. 2013;31:509-15.

15. Serour F, Ben-Yehuda Y, Boaz M. EMLA cream prior to digital nerve block for ingrown nail surgery does not reduce pain at injection of anesthetic solution. Acta Anaesthesiol Scand. 2002;46:203-6.

16. Kayalar M, Bal E, Toros T, Ozaksar K, Gurbuz Y, Ademoglu Y. Results of partial matrixectomy for chronic ingrown toenail. Foot Ankle Int. 2011;32:888-95.

17. Öztürkcan S, Ermertcan AT, Eser E, Sahin MT. Cross validation of the Turkish version of dermatology life quality index. Int I Dermatol. 2006;45:1300-7.

18. Itakura A, Tani Y, Kaneko N, Hide M. Impact of chronic urticaria on quality of life and work in Japan: results of a real-world study. J Dermatol. 2018;45:963-70.

19. Kouris A, Armyra K, Christodoulou C, Sgontzou T, Karypidis D, Kontochristopoulos G, et al. Quality of life psychosocial characteristics in Greek patients with leg ulcers: a case control study. Int Wound J. 2016;13:744-7.

20. Lindberg M, Bingefors $K$, Meding B, Berg M. Hand eczema and health-related quality of life: a comparison of EQ-5D and the Dermatology Life Quality Index (DLQI) in relation to the Hand Eczema Extent Score (HEES). Contact Dermatitis. 2013;69:138-43.

21. Zhang M, Zhang N. Quality of life assessment in patients with alopecia areata and androgenetic alopecia in the People's Republic of China. Patient Prefer Adherence. 2017;11:151-5.

22. Baran R. The nail in the elderly. Clin Dermatol. 2011;29:54-60.

23. Erpolat S, Eser A, Kaygusuz I, Balci H, Kosus A, Kosus N. Nail alterations during pregnancy: a clinical study. Int J Dermatol. 2016;55:1172-5.

24. Tsunoda M, Tsunoda K. Patient-controlled taping for the treatment of ingrown toenails. Ann Fam Med. 2014;12:553-5. 